\title{
Compulsive hoarding as a function of money attitudes
}

\begin{abstract}
Compulsive hoarding is a disorder that results from excessive accumulation of objects and inability to downsize. To predict compulsive hoarding behavior, a survey consisting of impulsive buying, compulsive buying, external consumer locus of control, and money scripts was administered to 409 college students in Southern Nevada.The results suggested that the compulsive hoarder agglomerates both objects and assets, exhibits an external consumer locus of control (E-CLOC), and purchases goods on impulse. Money worship was predictive of African-American and Asian hoarders, whereas impulsive buying was predictive of Hispanic hoarders. Money scripts were highly influential of hoarding behavior especially because each money script positively correlates with hoarding. Although compulsive buying and hoarding were slightly positively correlated, it was not predictive of hoarding behavior, thereby indicating an idiosyncrasy between the two purchasing disorders.
\end{abstract}

Keywords: compulsive hoarding, money scripts, money attitudes, consumer locus of control, impulsive buying, compulsive buying, obsessive-compulsive disorder
Volume 4 Issue 4 - 2015

\author{
Brittaney Benson Townsend, N Clayton \\ Silver \\ Department of Psychology, University of Nevada, Las Vegas, USA
}

Correspondence: N. Clayton Silver, Department of

Psychology, University of Nevada, Las Vegas, USA,

Emailfdnsilvr@unlv.nevada.edu

Received: December 16, 2015 | Published: December 19, 2015

\section{Introduction}

The increased consumer interest in hoarding behavior has sparked empathy and curiosity in the psychological research community. The Learning Channel's (TLC) profound exposure of hoarders on "Hoarding: Buried Alive," averaged nearly 1.5million views in 2010 during the show's first season. The network has renewed the show for five consecutive seasons and continues to air the program with positive consumer ratings. ${ }^{1}$ The population prevalence of hoarding is estimated to be $5.3 \%$ with evidence suggesting that the behavior may be genetically linked. ${ }^{2,3}$ The relevance of hoarding today is enhanced by pop culture influence, but delineation of hoarding from other forms of extreme shopping has received mixed results in the mainstream literature.

Compulsive hoarding is defined as the excessive accumulation of goods that non-hoarders would perceive as having negligible value. ${ }^{4}$ Hoarders agglomerate items to the degree that living spaces are no longer functional due to extreme clutter and unsuccessful attempts to downsize. ${ }^{5}$ Essentially, the home of a hoarder becomes a packed storage facility with no room left for intended functions of the area such as cooking in the kitchen or bathing in the bathtub.

An additional consequence of hoarding, besides the obvious clutter, includes severe anxiety. Hoarders often panic when others threaten their possessions by moving, touching, or throwing the items away. Furthermore, hoarders also claim to feel immense guilt because their insecurities regarding material goods foster inadequate, shared living space with their loved ones. Residents in the home all suffer from inhibited efficiency while attempting to move around the clutter, and experience the sense of being overwhelmed. More seriously, others living in the hoarding home may be especially susceptible to disease because of the excessive trash and the subsequent presence of rodents and insects. Moreover, hoarders also suffer from social deprivation. Loved ones may choose to leave the hoarder, thereby making the hoarder feel disinclined to invite new friends into their catastrophic homes because they are ashamed of their living conditions. ${ }^{4}$ In sum, hoarding habits are detrimental to the individual's health and the health of others in their proximate surroundings. Hoarders do not intentionally harm their loved ones through their dysfunctional behavior, but rather the expression of internal cognitive processing deficits fosters a harmful situation.

\section{Perfectionism and memory issues}

Frost et al., ${ }^{4}$ traced the roots of hoarding behavior to information processing deficits, problems in forming emotional attachments, behavioral avoidance, and erroneous beliefs about the nature of possessions. Specifically, hoarders struggle to correctly form organized, cognitive schemas. To a hoarder, multiple objects cannot be lumped into broad categories because each and every object, from a broken water bottle to a scribbled note on the back of an envelope, is unique. For example, a non-hoarder may be able to categorize their bottoms into dress pants, jeans, and sweat pants, but a hoarder will subdivide categories aimlessly. If a hoarder attempts to categorize their bottoms, they may form groups of black dress pants with four pockets, black dress pants with two pockets, black dress pants with two pockets sorted by designer, until eventually, each and every pair of pants is so finely described that each item has its own category. Items that are given such descriptive attention cannot be lumped together because the object loses some of its unique value. Thus, when sorting through their clutter, hoarders may not make progress because they struggle to form sustainable, cognitive categories. Frost et al., ${ }^{4}$ provided an illustrative example in their therapy practice with hoarders. One of their clients was asked to sort some of her household goods into three boxes: display, discard, and go through later. The client felt compelled to make two additional boxes for items she wanted to: "immediately go through" and "immediately-immediately go through." Despite her efforts, the client neither sorted through her three "go through later" boxes, nor could she remember which items she had placed in the boxes. ${ }^{4}$ Therefore, hoarders suffer from two cognitive deficits: perfectionism and insufficient memory.

In their conflict with perfectionism, hoarders struggle to estimate the value of an object and sort the object into piles of comparable items in a reasonable time frame. Hoarders demonstrate exceptional indecisiveness and procrastination perhaps due to a fear of making mistakes; a notion linked closely to perfectionism. ${ }^{6}$ When attempting 
to organize or downsize, hoarders examine an object for an extensive period of time and usually just move the object to a different pile. Hoarders struggle to make permanent decisions (such as throwing away an object) because they experience high anxiety from losing a piece of their memory and identity. Hoarders typically attach a sentimental value to most of their items, making any attempt to clear the home futile and frustrating. ${ }^{4}$

In addition to perfectionist constraints, hoarder difficulties include memory-inhibited downsizing efforts. Often, hoarders are guilty of keeping irrelevant, written texts such as old newspapers and notes on scrap paper. Compulsive hoarders have very little confidence in their memory and exaggerate the importance of needing old information on-hand. ${ }^{7}$ If texts were to be discarded, then the hoarder would likely panic because that information would be lost forever and the individual does not believe they could recall the material, should they ever need it. ${ }^{4}$ Hartl et al., ${ }^{7}$ found that compulsive hoarders demonstrated less verbal learning, spatial learning, and free recall than non-hoarder controls. Furthermore, the hoarders were less effective at using organizational strategies on the tests employed (e.g., Rey-Osterrieth Complex Figure Test and the California Verbal Learning Test). The study also suggested that hoarding should be delineated as a separate disorder apart from the traditional obsessive -compulsive disorder (OCD). ${ }^{7}$

\section{Obsessive compulsive relations}

The mainstream literature demonstrated associations among hoarding, OCD, and obsessive-compulsive buying behavior. OCD manifests as repetitive behaviors driven by intrusive, recurrent, and persistent thoughts, while eliciting anxiety for the individual. ${ }^{8}$ Compulsive buying is an insatiable urge to purchase luxury goods in an effort to quell negative emotions from some external stressor. ${ }^{9-11}$ To date, there is no specific diagnosis in the DSM-V for compulsive buying, but hoarding has received recognition as a separate disorder from OCD. ${ }^{12}$

Samuels et al., ${ }^{3}$ claimed that individuals diagnosed with OCD have a $30 \%$ comorbidity rate with compulsive hoarding. Compulsive hoarders are differentiated from OCD patients usually because compulsive hoarders do not suffer from contamination, aggressive, and symmetry compulsions that classical OCD patients endure. ${ }^{13}$ Specifically, hoarders do not obsess over the cleanliness of their environment, scenarios of severely harming others do not intrude their thoughts, and they do not obsess about spatial arrangements of their possessions.

Individuals who are diagnosed with obsessive-compulsive hoarding have a $75 \%$ chance of also being diagnosed with obsessivecompulsive buying: ${ }^{14}$ however, as many as half of all hoarders and one-third of compulsive buyers do not have OCD. ${ }^{3,13}$ Compulsive buyers are infamous for irresponsible spending and credit card abuse, ${ }^{15}$ but several authors have claimed hoarding disorder manifests from material deprivation in childhood, such that children who suffer financial hardship, may become object accumulators and moneysquandering adults. ${ }^{3,4,16}$ Interestingly, Hezel et al., ${ }^{17}$ measured financial prudence and childhood financial hardship in conjunction with hoarding and found no association. Compulsive buyers may develop into hoarders later in life, given that compulsive buying and hoarding are often comorbid phenomena. ${ }^{18}$ The case may be that hoarders begin their cycle as excessive shoppers by exhibiting compulsive buying behavior, but then become hoarders after their products have accumulated with age. ${ }^{3}$ In fact, the average age of onset of hoarding symptoms is about 34 years old, but the average compulsive buying onset age is documented between 18 and 24years old. ${ }^{19,20}$ Thus, empirical evidence suggests that hoarding and compulsive buying are subsets of a spectrum of obsessive-compulsive-type disorders occurring at different stages of life.

\section{Aligning compulsive and impulsive buying with hoarding}

Both hoarders and compulsive buyers are described as lowincome individuals and subtypes of OCD spectrum disorders. ${ }^{3,21,22}$ Like OCD, compulsive buyers are overrepresented in samples with impulse-control disorder (ICD) given a $96 \%$ overlap. Individuals with ICD experience uncontrollable urges to take risks without regard for consequences. ${ }^{23}$ In fact, individuals diagnosed with a lifetime ICD were more likely to possess hoarding and symmetry obsessions ${ }^{24}$ In particular, kleptomania is an ICD in which individuals feel the urge to steal items not necessary for one's well-being (e.g., jewelry, electronics, makeup). Kleptomaniacs may choose to give away, dispose of, or return stolen items to the store; however, many individuals choose to hoard their goods if they are not compelled by guilt to discard the stolen items. ${ }^{25}$ In addition, individuals diagnosed with ICD were more likely to report highly disruptive obsessive behaviors with regard to OCD symptoms. ${ }^{25}$ Because hoarding behavior highly overlaps with compulsive buying behavior and because compulsive buying behavior highly relates with impulsive behavior, hoarders are more likely to score high on both the impulsive buying and the obsessivecompulsive buying factors of the Richmond Compulsive Buying Scale. ${ }^{23}$

a) H1A: An individual with a high score on the obsessivecompulsive buying factor of the Richmond Compulsive Buying Scale will score high on hoarding subscale of the Klontz Money Behavior Inventory.

b) H1B: An individual with a high score on the impulsive buying factor of the Richmond Compulsive Buying Scale will score high on hoarding subscale of the Klontz Money Behavior Inventory.

The prevalence of compulsive buying behavior in the U.S. is estimated at about $5.8 \%$ with $80 \%$ of compulsive buyers being women. ${ }^{11,22}$ In particular, Frost et al., ${ }^{26}$ found that compulsive buying activity was more frequent in women who exhibited hoarding behavior.

c) H2: For women, scores on the Richmond Compulsive Behavior Scale will predict scores on the hoarding subscale of the Klontz Money Behavior Inventory

Another cognitive factor that influences compulsive buying is locus of control. Consumer locus of control occurs via two orientations: internal and external, and may be measured via the Consumer Locus of Control Scale. ${ }^{27}$ The locus of control orientation is a person's attribution of success and failure to either the self (internal) or something other than the self (external). ${ }^{27}$ A consumer who is internally oriented will demonstrate active budgeting practices and is usually more financially secure; whereas a consumer who is externally oriented is likely to exhibit compulsive buying behavior and defer spending consequences for as long as possible through the accumulation of credit card debt. ${ }^{15,28}$ Watson ${ }^{28}$ reported that the proportion of compulsive buyers was significantly higher in the external locus of control orientation than the internal locus of control orientation. The Consumer Locus of Control Scale ${ }^{27}$ has not been examined in conjunction with a hoarding scale. Hence, it is hypothesized that external consumer locus of control will positively correlate to hoarding scores on the Klontz Money Behavior Inventory. ${ }^{29}$ 
d) H3: An individual scoring high on the external consumer locus of control factor of the Consumer Locus of Control Scale will score high on hoarding subscale of the Klontz Money Behavior Inventory

Moreover, it is also expected that external consumer locus of control will contribute a significant amount of variance to the regression model predicting hoarding scores. A positive correlation between the Hoarding Scale ${ }^{30}$ and Rotter's Locus of Control Scale ${ }^{31}$ has been demonstrated in the literature only for external locus of control, but not for internal locus of control. ${ }^{32}$

e) H4: External orientation of the Consumer Locus of Control Scale will contribute a significant amount of variance in predicting hoarding scores

Compulsive buying and other forms of extreme shopping are closely related to cognitive money attitudes measured with the Money Attitude Scale ${ }^{15,33}$ and the Money Beliefs and Behavior Scale. ${ }^{34,35}$ Specifically, compulsive buying is positively correlated with money as power-prestige and money anxiety attitudes; and negatively correlated with price sensitivity attitudes. ${ }^{15}$ However, compulsive buying has yet to be measured in conjunction with the short Money Beliefs and Behaviors Scale. ${ }^{36}$ Furnham et al., ${ }^{37}$ investigated their compensation factor in an effort to analyze people who shop for emotional regulation. They found a weak positive correlation with money is power and freedom, a mild negative correlation with money is security, and a mild positive correlation with money is love. In addition, Furnham et al., ${ }^{37}$ also found no correlation between money hoarding (frugalness) with the compensation factor.

A recent money attitudes measure, namely the Klontz Money Script Inventory, consists of money avoidance, money worship, money status, and money vigilance. ${ }^{29}$ Money avoiders associate money with negative feelings such as fear, disgust, or anxiety. Money worshippers, in contrast, associate money with extremely positive feelings including a better life, and viable solutions to their dilemmas. Individuals who associate money with status are very materialistic and use their wealth to impress others and demonstrate dominance. Finally, for money vigilance, money must be saved, while finances are kept secret from the knowledge of others. ${ }^{38}$ Given that hoarders save a plethora of objects, perhaps they will exhibit hoarding behaviors with money directly.

f) H5: An individual exhibiting high scores on the money vigilance factor of the Klontz Money Scripts Inventory will score high on the hoarding subscale of the Klontz Money Behavior Inventory

Because compulsive buyers and hoarders are both types of extreme shopping disorders, it is hypothesized that money attitudes, measured by the Klontz Money Script Inventory ${ }^{38}$ will predict hoarding scores on the Klontz Money Behavior Inventory. Money avoidance and money worship scripts explained a small $(10 \%)$ portion of the variance in hoarding scores, ${ }^{39}$ but their regression analysis was not repeated between sexes and among different ethnicities.

Women are usually characterized as managing household budgets. ${ }^{40}$ In a study of married couples, wives used household finances for their personal spending especially if they earned less money than did their husbands. ${ }^{40}$ Purchasing food, children's clothing, school expenses, and gifts for others were chores delegated to the wives by the husbands. Thus, wives may micromanage marital finances and make many decisions with regard to budgeting, in order to best satisfy the family's needs. In contrast, husbands were responsible for paying inconsistent and impulsive activities such as repairs, decorating, dining out, and drinks at the bar. With support drawn from marital finance control and management, ${ }^{40}$ money vigilance (savings and budgeting behavior) will be more characteristic of women than men. Also, money avoidance (fearful and anxious feelings about money) will be more characteristic of men than women because men choose to give their money away in an effort to delegate spending responsibilities to women. When wives earned more money than their husbands, they continued to purchase food, clothing, and other resources. Moreover, they did not delegate that responsibility to their husbands. Thus, women may inherently enjoy managing money whereas men do not. If we consider hoarding behavior as an excessive frequency of ordinary purchasing behavior, then we may hypothesize the following:

g) H6: Money vigilance scores from the Klontz Money Script Inventory will contribute a significant amount of variance in predicting female hoarding scores.

h) H7: Money avoidance scores from the Klontz Money Script Inventory will contribute a significant amount of variance in predicting male hoarding scores

\section{Differences between compulsive buyers and hoarders}

Both hoarders and compulsive buyers suffer from excessive purchasing, but the difference between the two expressions of compulsive behaviors lies in the reason for acquiring purchases and how the goods are used after the purchase. Hoarding behavior occurs as a result of cognitive deficits exacerbated by an inability to downsize. Compulsive buying behavior is elicited by internal feelings of anxiety, in which the consumer feels possessed to purchase in an effort to quell angst. ${ }^{15,33}$

Beyond the differing cognitive processes in hoarder and compulsive buyer purchasing behavior, the types of goods that hoarders acquire are markedly different from those of compulsive buyers. Compulsive buyers gravitate towards items that enhance their status (mostly luxury goods) to improve their lacking internal confidence. After the purchase, the compulsive buyer presumes to pretentiously display their goods in order to demonstrate social dominance over others. ${ }^{11}$ Because compulsive buyers use goods to enhance their power and prestige within in their community, ${ }^{15,33}$ they physically interact with their luxury goods on a regular basis. In contrast, hoarders acquire items regardless of their actual value because they lack the cognitive ability to organize, and they enable delusions regarding utilitarian value of items and their inflated uniqueness. ${ }^{4}$ Because hoarders accumulate so many items that become piled on top of one another, physical interaction with their goods is relatively low. Nonetheless, hoarders still maintain a strong sentimental attachment to their belongings regardless of how little they interact with their items or their monetary worth. ${ }^{4}$ Thus, the acquisition of objects provides hoarders and compulsive buyers with internal comfort, but differences exist between hoarders and compulsive buyers in the types of goods acquired and the physical product-buyer interaction.

The money status factor of the Klontz Money Script Inventory is a construct reflective of the belief that financial success is the key to self-confidence. Individuals who resonate with the money status belief pretend to have more money than they actually do and use credit cards as a means to purchase status-enhancing goods from designer or luxury-related brands. Because hoarders do not buy goods for the intent of enhancing social status, it is likely that they will not perceive money as a means to impress others.

i) H8: An individual scoring high on the money status factor of the Klontz Money Script Inventory will score low on the hoarding subscale of the Klontz Money Behavior Inventory. 


\section{Method}

\section{Participants}

A sample of 409 undergraduate psychology students: 112 males, 296 females, and 1 student who did not volunteer their sex; 174 Caucasian, 31 African-American, 108 Hispanic, and 96 Asian (mean age $=20.34$ years, $\mathrm{SD}=4.89$ years; range $16-55$ years) from the University of Nevada, Las Vegas volunteered to complete a series of money-oriented questionnaires as partial fulfillment toward their research participation requirement for the General Psychology course.

\section{Materials}

As part of a larger study, four financial behavior scales were used. The Compulsive-Buying Scale ${ }^{23}$ is a 6-item measure of equally compulsive buying and impulsive buying factors with a reported overall Cronbach's $\alpha$ of .84. The overall Cronbach's $\alpha$ in the present study was also .84 . Compulsive buying, represented by 3 items had a reported Cronbach's $\alpha$ of $.99^{23}$ whereas it was .82 in the present study. Impulsive buying consisted of 3 items with a Cronbach's $\alpha$ of $.78,{ }^{23}$ and a Cronbach's $\alpha$ of .82 in the present study.

The Consumer Locus of Control Scale ${ }^{27}$ is a 14-item measure on a 5-point scale in which the higher a participant's score, the more externally oriented they are. Six items pertain to the internal consumer locus of control orientation with a reported Cronbach's $\alpha$ of $.76,{ }^{27}$ whereas it was only .63 in the present study. The remaining 8 items pertained to external consumer locus of control orientation with a reported Cronbach's $\alpha$ of .77, and a Cronbach's $\alpha$ of .74 in the present study. Of note, internal and external consumer locus of control were not divided by factors, but rather a high score on the Consumer Locus of Control Scale indicated external orientation as opposed to internal orientation.

The Klontz Money Script Inventory ${ }^{38}$ is a 51-item measure of money scripts, defined as one's cognitive affiliations with money, with a reported Cronbach's $\alpha$ of .84 for the overall scale.In the present study, the overall Cronbach's $\alpha$ was computed at .87 . The money avoidance factor, represented by 15 items, had a reported Cronbach's $\alpha$ of .77. The Cronbach's $\alpha$ was .86 in the present study. The money worship factor, represented by 11 items, had a reported Cronbach's $\alpha$ of .77. The Cronbach's $\alpha$ was .84 in the present study. The money status factor, represented by 13 items, had a reported Cronbach's $\alpha$ of .77. The Cronbach's $\alpha$ was .80 in the present study. The money vigilance factor, represented by 4 items, had a reported Cronbach's $\alpha$ of .77. The Cronbach's $\alpha$ was only .57 in the present study.

The Klontz Money Behavior Inventory ${ }^{29}$ is a 53 -item measure of disordered financial habits. The overall Cronbach's $\alpha$ was not provided by Klontz et al., ${ }^{29}$ For the present study, the Cronbach's $\alpha$ was .72 . For the purpose of the present study, only the hoarding factor was used in analysis, with a reported Cronbach's $\alpha$ of $.91 .^{29}$ The Cronbach's $\alpha$ was .90 in the present study.

Finally, a series of demographics questions concerning sex, income, ethnicity, employment, age, birth order, student status, financial knowledge, religious, and political affiliation were given to the participants.

\section{Procedure}

All questionnaires were randomized via Qualtrics block settings to prevent user fatigue and general carry-over effects. The survey was administered online via Qualtrics and could be completed from any location via a computer so as to maximize student privacy and free response. The majority of participants completed the survey between 30 and 90 minutes.

\section{Results}

To address the hypotheses presented in the introduction, correlations were computed to confirm or disprove the experimental predictions. Moreover, in order to keep False Discovery Rate under control when testing statistical significance, we used the step-up procedure by Benjamini et al., ${ }^{41}$ Hypothesis $1 \mathrm{~A}$ was supported by statistically significant correlations $r=.157, p<.01$ between compulsive buying and hoarding factors. Hypothesis 1B was supported by statistically significant correlations $r=.255, p<.01$ between impulsive buying and hoarding factors. Therefore, although the correlations are considered low, ${ }^{42}$ the greater the compulsive and impulsive buying scores, the higher the compulsive hoarding scores.

To predict compulsive hoarding behavior, a multiple regression analysis was performed to examine compulsive buying, impulsive buying, consumer locus of control, and money script correlates with compulsive hoarding across sexes and ethnicities. Although there was a slight amount of collinearity between the obsessive-compulsive and impulsive buying factors of the Richmond Compulsive Buying Scale, ${ }^{23}$ we opted to examine both variables in the equation.

Hence, the independent variables for the overall multiple regression model consisted of the two factors: compulsive buying and impulsive buying from the Compulsive-Buying Scale, ${ }^{23}$ the overall score of the Consumer Locus of Control Scale, ${ }^{27}$ and the four factors: money avoidance, money worship, money status, and money vigilance from the Klontz Money Script Inventory The dependent variable was the hoarding factor from the Klontz Money Behavior Inventory. ${ }^{29}$ The overall model was statistically significant, $R=$ $.387, R 2=.150, F(7,401)=10.08, p<.01$. Money vigilance $t(401)$ $=2.339, p<.05$, consumer locus of control $t(401)=2.898, p<.01$, and impulsive buying $t(401)=3.012, p<.01$ each contributed statistically significant amounts of variance to the overall equation.

Subsequent multiple regressions were computed separately for each sex and ethnicity. For males, the overall model was statistically significant, $R=.499, R 2=.249, F(7,104)=4.925, p<.001$. Money avoidance $t(104)=2.773, p<.01$ and impulsive buying $t(104)=$ $2.697, p<.01$ each contributed statistically significant amounts of the variance to the overall equation. For females, the overall model was statistically significant, $R=.371, R 2=.138, F(7,288)=6.565, p<.001$. Money vigilance $t(288)=2.77, p<.01$ and external consumer locus of control orientation $t(288)=2.697, p<.05$ each contributed statistically significant amounts of the variance to the overall equation. Thus, hypothesis 2 was not supported because compulsive buying scores did not predict hoarding scores for women.

For Caucasians, the overall model was statistically significant, $R=$ $.342, R 2=.117, F(7,166)=3.133, p<.01$. Only external consumer locus of control $t(166)=2.262, p<.05$ contributed a statistically significant amount of the variance to the overall equation. Although the ratio of the sample size to the number of predictors was low (less than 5), we opted to analyze results for the African-American ethnicity of the overall sample. For African-Americans, the overall model was statistically significant, $R=.689, R 2=.475, F(7,23)=2.973, p<.05$. Only money worship $t(23)=2.244, p<.05$ contributed a statistically significant amount of the variance to the overall equation. For Hispanics, the overall model was statistically significant, $R=.455, R 2$ $=.207, F(7,100)=3.724, p<.01$. Only impulsive buying $t(100)$ $=2.368, p<.05$ contributed a statistically significant amount of the 
variance to the overall equation. For Asians, the overall model was slightly statistically significant, $R=.428, R 2=.183, F(7,88)=$ $2.814, p<.05$. Only money worship $t(88)=2.179, p<.05$ contributed a statistically significant amount of the variance to the overall equation.
Hypothesis 3 was supported, demonstrating that external consumer locus of control orientation is significantly and positively correlated with hoarding behavior scores, $r=.215, p<.001$ (see Table 1). Therefore, the greater the external consumer locus of control orientation, the higher the compulsive hoarding scores.

Table I Correlation matrix for the factors of the Richmond Compulsive Buying Scale ${ }^{23}$ and the Money Script Inventory ${ }^{38}$ for the overall sample

\begin{tabular}{|c|c|c|c|c|c|c|c|c|}
\hline Overall & $\mathbf{H}$ & OCB & IB & CLOC & MA & MW & MS & MV \\
\hline $\mathbf{H}$ & I & & & & & & & \\
\hline OCB & $.157 * *$ & I & & & & & & \\
\hline IB & $.255^{* *}$ & $.555^{* *}$ & I & & & & & \\
\hline CLOC & $.215^{* *}$ & $.191 * *$ & $.265^{* *}$ & I & & & & \\
\hline MA & $.173^{* *}$ & .012 & .004 & $.133^{* *}$ & 1 & & & \\
\hline MW & $.186 * *$ & $.172 * *$ & $.225^{* *}$ & $.143^{* *}$ & $.138 * *$ & I & & \\
\hline MS & $.159 * *$ & $.262 * *$ & $.097^{*}$ & $.202 * *$ & $.322 * *$ & $.45 I^{* *}$ & I & \\
\hline MV & $.155^{* *}$ & .066 & .025 & $-.130 * *$ & $.200 * *$ & $.229 * *$ & $.155^{* *}$ & 1 \\
\hline
\end{tabular}

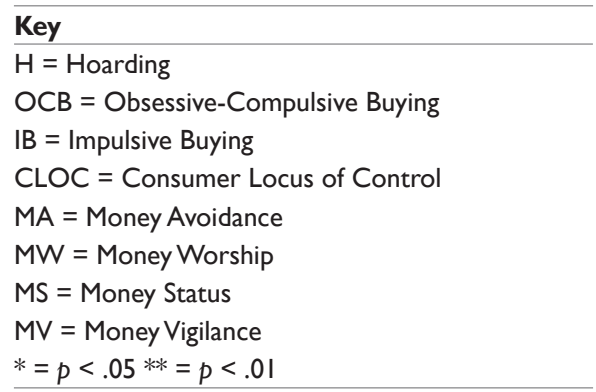

Hypothesis 4 was supported because consumer locus of control scores contributed a significant amount of variance in predicting hoarding scores. Interestingly, the obsessive-compulsive buying dimension did not adequately predict hoarding in the overall model $t(408)=-0.086, p>.05$.

Hypothesis 5 was supported with statistically significant positive correlations for hoarding among all four factors of the Klontz Money Script Inventory, ${ }^{38}$ including money avoidance $r=.173, p<.01$; money worship $r=.186, p<.01$; money status $r=.159, p<.01$; and money vigilance $r=.155, p<.01$. Again, although the correlations are low, the higher the money avoidance, money worship, money status, and money vigilance scores, the higher the compulsive hoarding scores.

Hypotheses 6 and 7 were supported. Money vigilance scores contributed a significant amount of variance for hoarding scores for women and money avoidance scores contributed a significant amount of variance for hoarding scores in men.

Hypothesis 8 was not supported because hoarding scores did not negatively correlate with money status scores. In contrast, money status scores positively correlated with hoarding scores $r=$ $.159, p<.01$. Yet, it should be noted that all correlations accounted for only $2-6 \%$ of the variance.

\section{Discussion}

Obsessive compulsive buying behavior may influence attitudinal differences towards money and hoarding behavior. Individuals execute irresponsible spending behaviors when they make purchases other than to satisfy an immediate need. Hoarders make purchases to enhance their excessive collection of goods, while maintaining delusional beliefs about object utility. Compulsive buyers make purchases for the sake of social dominance and the artificial dissemination of luxury. Hoarders may be exceptionally inclined to save money and keep their finances secret because of their predisposition to shelter material; however, the notion of worshipping money or using dollars to buy status is rather uncharacteristic of hoarders and fits the profile of a compulsive buyer instead. Because hoarding correlated with all four measures of money scripts (See Table 1) including money avoidance, money worship, money status, and money vigilance, ${ }^{38}$ perhaps this is evidence for the theory that compulsive buyers develop into hoarders later in life due to the massive accumulation of goods, if they are unable to downsize. ${ }^{18}$ Alternatively, the explanation for correlations with all types of money scripts may be derived from a hoarder's cognitive inability to categorize objects. Perhaps, when answering survey questions, hoarders consider their money scripts from myriad perspectives including how they managed money previously as compulsive buyers, and how they manage money currently as hoarders. Because hoarders fear making mistakes, they have difficulty making decisions, so the result is an association with all types of money scripts.

With regard to external consumer locus of control and impulsive buying dimensions that significantly loaded onto the multiple regression predicting hoarding, results supported the notion that extreme shopping behavior more generally overlaps with ICD as opposed to OCD. ${ }^{23}$ Thus, hoarders and compulsive buyers may exist as sublevels of OCD disorders, but all may be more idiosyncratic than the mainstream literature purports. Furthermore, actions executed as a result of impulsive decisions strongly relate to external consumer locus of control. Consumers with an external orientation do not shop with consequences in mind. When hoarders purchase new items, they buy goods on impulse with no care for the negative consequences of adding to their hoard.

In terms of sex differences, Samuels et al., ${ }^{3}$ found double the hoarders in males as opposed to females. In addition, Wheaton et al., ${ }^{43}$ reported that male hoarders demonstrated increased social phobia compared to women. However, female hoarders had a greater prevalence of anxiety, depression, and ADHD. ${ }^{12}$ The current 
research showed that money avoidance was a significant predictor for male's hoarding scores, whereas money vigilance was a significant predictor for female's hoarding scores. Because male hoarders fear public exposure, it is likely they associate money, a symbol of public commerce, with negative feelings ${ }^{43}$ Money exchange requires a social interaction, in which male hoarders do not confidently participate. In addition, purchasing goods for the household in marriage is often delegated to wives perhaps due to a general male dislike for shopping. ${ }^{40}$ In contrast, female hoarders are more characterized by general nervousness. Money vigilance might be associated for females because this construct is closely related to financial concern and worry. ${ }^{39}$ If female hoarders have excessive anxiety, then they may cherish money and become anxious if it is spent. According to Pahl, ${ }^{40}$ leisure spending in marriage is often considered as an entitled indulgence for males and an unessential indulgence for females. Some wives reported feeling guilty after spending money on themselves because the money for leisure came from the household budget more often than from their own finances. Thus, women may feel more inclined to experience anxiety when making purchases for themselves because they must buy goods for both the home and their children with a fixed allowance from their husband, before they can afford to purchase goods for themselves. In the existing literature, hoarding has not generally been delineated by ethnic background; however, certain ethnic differences in money attitudes have been documented. For Caucasians, money is often used for individualistic purposes in an effort to sustain one's needs or to enhance individualism and social dominance ${ }^{44}$ External consumer locus of control was a significant predictor for Caucasian hoarders because money is spent for the sake of social competition without consideration of debt or other measures of financial turmoil. In terms of African-Americans, money worship was a significant predictor because of deeply rooted cultural beliefs that more money equates to more power. For African-Americans, social class (largely determined by income) provides the means to enhance status, control resources, and defend against threats..$^{45}$ Thus, African-American hoarders may hold this particularly engrained belief and generalize asset-hoarding to object-hoarding. For Hispanic hoarders, impulsive buying was a significant predictor because money is more of a collective means of expression. ${ }^{44}$ Hispanic consumers often purchase items with collectivist intentions (such as gift-giving) and generate money within the family tree (often by working in a family business). Thus, a Hispanic hoarder would not develop with individualist money scripts as hypothesized by Medina $t$ eal. ${ }^{46}$ but instead behave as a result of impulsive purchasing due to their excessive credit card use compared to Caucasians. In fact, previous research indicated that Hispanics scored lower on the retention/time dimension of the Money Attitude Scale, ${ }^{33}$ suggesting that Hispanics may be poor financial planners because they are unable to delay gratification. Thus, Hispanics are inclined to make impulsive purchasing decisions because of their general aversion to long-term financial planning, and a preference for immediate rewards. In consideration of Asians, money worship was a significant predictor of hoarding scores because money is a means to a better life. In Asian countries, many citizens believe that democracy is achieved via economic growth, and financial plenty will lead to humanitarian political reforms for the better protection of human rights. ${ }^{47}$ Because monetary growth is directly associated with a better, collective society, asset-hoarding may generalize to object hoarding for the Asians as well.

With regard to the limitations of the present study, it should be noted that the entire sample consisted of college students with very few African-Americans $(n=31)$. Although the impetus of the current research was to examine ethnicities with regard to financial attitudes and hoarding behaviors, the small number of African-Americans limits statistical power needed to generalize results to the population at large. Furthermore, because the sample consisted of only college students, the generalization of these results may be limited to similar groups. Nonetheless, there has been little to no research examining variations in hoarding predictors across ethnicities, until now. The present study also supports an association between hoarding and money philosophies, whereas other authors were unable to find a significant statistical connection. ${ }^{17}$ Yet, these correlations were small and statistical significance was augmented by a larger overall sample size.

Future research projects in hoarding could include a wider spectrum of ages along with higher sample sizes for minorities. Furthermore, perhaps distinct sample groups for clinical-level hoarders and non-hoarders may yield different results in terms of money attitudes. An interesting longitudinal study would be one that tracks impulsive buyers and compulsive buyers, and then follows up with the subjects to determine which demographic and psychographic qualities predict hoarding behavior later in life. In addition, because hoarding has become a mainstream term in common conversation, perhaps researchers need two different scales for object accumulators and extreme hoarders. In general, disordered money behaviors are becoming more distinct as research progresses. For example, Bose et al. ${ }^{18}$ defined eight forms of extreme buyers including compulsive, impulsive, excessive, fixated, and acquisitive buyers; hoarders, collectors, and stockpilers. Perhaps many (or all) of these forms of consumers are somewhat independent, thereby achieving mixed results and weak correlations in the literature. ${ }^{37}$ Therefore, more delineated measurement tests are needed to accurately assess the predictors of specific extreme shopping behaviors such as hoarding. Finally, an analysis of clinical hoarders' spending habits (apart from their conceptual money attitudes) may confirm the present study's findings and provide more general implications to the hoarding population.

\section{Acknowledgments}

None.

\section{Conflicts of interest}

Author declares there are no conflicts of interest.

\section{Funding}

None.

\section{References}

1. Levine S. TLC holds on to 'Hoarding'. Daily Variety. 2010;307(23):4.

2. Iervolino AC, Perroud N, Fullana MA, et al. Prevalence and heritability of compulsive hoarding: A twin study. Am J Psychiatry. 2009;166(10):1156-1161.

3. Samuels JF, Bienvenu OJ, Grados MA, et al. Prevalence and correlates of hoarding behavior in a community-based sample. Behav Res Ther. 2008;46(7):836-844.

4. Frost RO, Hartl TL. A cognitive-behavioral model of compulsive hoarding. Behav Res Ther. 1996;34(4):341-350.

5. Tolin DF, Frost RO, Steketee, G. Buried in treasures: Help for compulsive acquiring, saving, and hoarding (2nd edn), Oxford University Press, New York, USA. 2014.

6. Frost RO, Marten P, Lahart C, et al. The Dimensions of Perfectionism. Cognitive Therapy and Research. 1990;14(5):449-468. 
7. Hartl TL, Frost RO, Allen GJ, et al. Actual and perceived memory deficits in individuals with compulsive hoarding. Depress Anxiety. 2004;20(2): 59-69.

8. Bokor G, Anderson PD. Obsessive-compulsive disorder.J Pharm Pract. 2014;27(2):116-130.

9. Faber RJ, O'Guinn TC. A Clinical screener for compulsive buying. Journal of Consumer Research. 1992;19(3):459-469.

10. Sang-Hee S, Yun-Jung C. A model of compulsive buying: Dysfunctional beliefs and self regulation of compulsive buyers. Social Behavior \& Personality: An International Journal . 2012;40(10):1611-1624.

11. Workman L, Paper D. Compulsive buying: A theoretical framework. Journal of Business Inquiry: Research, Education, \& Application. 2010;9(1):89-126.

12. American Psychiatric Association. Diagnostic and statistical manual of mental disorders. (5thedn), American Psychiatric Publishing, Arlington, USA. 2013.

13. Pertusa A, Fullana MA, Singh S, et al. Compulsive hoarding: OCD symptom, distinct clinical syndrome, or both?Am $J$ Psychiatry. 2008;165(10):1289-1298.

14. Mueller A, Mueller U, Albert P, et al. Hoarding in a compulsive buying sample. Behav Res Ther. 2007;45(11):2754-2763.

15. Roberts JA, Jones E. Money attitudes, credit card use, and compulsive buying among American college students. Journal of Consumer Affairs. 2001;35(2):213-240.

16. Kellett S, Greenhalgh R, Beail N, et al. Compulsive hoarding: An interpretative phenomenological analysis.Behav Cogn Psychother. 2010; 38(2):141-155.

17. Hezel DM, Hooley JM. Creativity, personality, and hoarding behavior. Psychiatry Research. 2014;220(1):322-327.

18. Bose M, Burns AC, Garretson Folse JA. "My fifty shoes are all different!" Exploring, defining, and characterizing acquisitive buying. Journal of Psychology and Marketing. 2013;30(7):614-631.

19. Grisham JR, Frost RO, Steketee G, et al. Age of onset of compulsive hoarding. J Anxiety Disord. 2006;20(5):675-686.

20. Yurchisin J, Johnson KKP. Compulsive buying behavior and its relationship to perceived social status associated with buying, materialism, self-esteem, and apparel-product involvement. Family and Consumer Sciences Research Journal. 2004;32(3):291-314.

21. Frost RO, Steketee G, Williams L. Compulsive buying, compulsive hoarding, and obsessive-compulsive disorder. Behavior Therapy. 2002;33(2):201-214.

22. Koran LM, Faber RJ, Aboujaoude E, et al. Estimated prevalence of compulsive buying behavior in the United States. Am J Psychiatry . 2006;163(10):1806-1812.

23. Ridgway NM, Kukar Kinney M, Monroe KB. An expanded conceptualization and a new measure of compulsive buying. Journal of Consumer Research. 2008;35(4):622-639.

24. Grant JE, Mancebo MC, Pinto A, et al. Impulse control disorders in adults with obsessive compulsive disorder. $J$ Psychiatr Res. 2006;40(6):494-501.

25. Grant JE, Odlaug BL, Wozniak JR. Neuropsychological functioning in kleptomania. Behav Res Ther. 2007;45(7):1663-1670.

26. Frost RO, Tolin DF, Steketee G, et al. Excessive acquisition in hoarding. $J$ Anxiety Disord. 2009;23(5):632-639.

27. Busseri MA, Lefcourt HM, Kerton RR. Locus of control for consumer outcomes: Predicting consumer behavior. Journal of Applied Social Psychology. 1998;28(12):1067-1087.
28. Watson S. Credit card misuse, money attitudes, and compulsive buying behaviors: A comparison on internal and external (LOC) consumers. College Student Journal. 2009;43(2):268-275.

29. Klontz B, Britt SL, Archuleta KL, et al. Disordered money behaviors: Development of the Klontz Money Behavior Inventory. Journal of Financial Therapy. 2012; 3(1)

30. Frost RO, Gross RC. The hoarding of possessions. Behav Res Ther: 1993;31(4):367-381.

31. Rotter JB. Generalized expectancies for internal versus external control of reinforcement. Psychol Monogr. 1966;80(1):1-28.

32. Frost RO, Hartl TL, Christian R, et al. The value of possessions in compulsive hoarding: Patterns of use and attachment. Behav Res Ther. 1995;33(8):897-902.

33. Yamauchi KT, Templer D. The development of a money attitudes scale. $J$ Pers Assess. 1982;46(5):522-528.

34. Furnham A. Many sides of the coin: The psychology of money usage. Personality and Individual Differences. 1984;5(5):501-509.

35. Hanley A, Wilhelm MS. Compulsive buying: An exploration into self-esteem and money attitudes. Journal of Economic Psychology. 1992;13(1):5-18.

36. Furnham A, Wilson E, Telford K. The meaning of money: The validation of a short money-types measure. Personality and Individual Differences 2012;52(6):707-711.

37. Furnham A, Von Stumm S, Fenton-O'Creevy M. Sex differences in money pathology in the general population. Soc Indic Res. 2015;123(3):701-711

38. Klontz B, Britt SL, Mentzer J, et al. Money Beliefs and Financial Behaviors: Development of the Klontz Money Script Inventory. The Journal of Financial Therapy. 2011;2(1):1-22.

39. Klontz B, Britt S. How clients' money scripts predict their financial behaviors. Journal of Financial Planning. 2012;25(11):33.

40. Pahl J. Household spending, personal spending and the control of money in marriage. Sociology. 1990;24(1):119-138.

41. Benjamini Y, Hochberg Y. Controlling the false discovery rate: A practical and powerful approach to multiple testing. Journal of the Royal Statistical Society. Series B.1995;57(1):289-300.

42. Cohen J. Statistical power analysis for the behavioral sciences. Academic Press, New York, USA. 2013.

43. Wheaton M, Timpano KR, Lasalle-Ricci VH, et al. Characterizing the hoarding phenotype in individuals with OCD: Associations with comorbidity, severity and gender. J Anxiety Disord .2008;22(2):243-252.

44. Falicov CJ. The cultural meanings of money: The case of Latinos and Anglo-Americans. American Behavioral Scientist. 2001;45(2):313-328.

45. Carter PL. "Black" cultural capital, status positioning, and schooling conflicts for low-income African American youth. Social Problems. 2003; 50(1):136-155

46. Medina JF, Saegert J, Gresham A (1996) Comparison of MexicanAmerican and Anglo-American attitudes toward money. Journal of Consumer Affairs 30(1): 124-145.

47. Peerenboom R (2004) Show me the money: the dominance of wealth in determining rights performance in Asia. Duke Journal of Comparative \& International Law 15(1): 75-152. 